\title{
Disentangling the perceived performance effects of publicness and bureaucratic structure: A survey- experiment
}

\section{Petra van den Bekerom*, Joris van der Voet ${ }^{*}$}

\begin{abstract}
Recent studies have examined whether, all else equal, there is a general tendency among citizens to perceive public service providers as lower performing than their private counterparts. As public organizations are commonly stereotyped as "bureaucracies," it is unknown whether the negative image of public organizations is caused by their publicness or by their structural bureaucratic characteristics. This article makes a novel contribution to the literature by disentangling these two variables, and examines to what extent the proclaimed negative effect of publicness on citizens' performance perceptions is dependent on citizens' perceptions regarding the bureaucratic structure of public organizations. This is investigated through a survey-experiment conducted among 422 Dutch undergraduate students in public administration. The main findings of the study are that we find no evidence for direct negative effects of publicness, and that the bureaucratic structure of the organization positively affects the degree in which citizens perceive public organizations to be equitable and responsive. The study informs future directions for BPA research on the performance effects of publicness by paying more attention to contextual variation and a more nuanced empirical assessment of the public-private distinction.
\end{abstract}

Keywords: Publicness, Organizational structure, Performance perceptions, Survey-experiment.

Supplements: $\underline{\text { Open data }}$

$\mathrm{B}$ ecause public organizations are often depicted as unwieldy organizations that are inefficient and obstructed by burdensome rules and regulations, citizens are believed to perceive the organizational performance of public organizations more negatively than the performance of private organizations (Marvel, 2015). Indeed, prior survey-experimental research (e.g. Hvidman \& Andersen, 2016; Hvidman, 2019) has demonstrated that citizens rate the perceived performance of public organizations lower on a multi-dimensional performance scale. In explaining this effect, the bureaucratic nature of public organizations features as a cause for negative performance perceptions. Public organizations are typically stereotyped as "bureaucracies," a term with a negative connotation that is often associated with inefficiency, ineffectiveness and irresponsiveness. However, because public organizations have become synonymous with "bureaucracy," it is unknown whether the negative image of public organizations is caused by their publicness or by their structural bureaucratic characteristics. In the present study, we aim to create further insight into the causal mechanisms that underlie the relationship between publicness and performance perceptions by attempting to disentangle the perceived performance effects of publicness and bureaucratic structure. In other words: are citizens' performance perceptions about private organizations equally affected by bureaucratic characteristics, and do public organizations

\footnotetext{
* Leiden University, the Netherlands

Address correspondence to Petra van den Bekerom at (p.e.a.van.den.bekerom@fgga.leidenuniv.nl)

Copyright: C 2021. The authors license this article under the terms of the Creative Commons Attribution 4.0

International License.
} 
that do not adhere to bureaucratic principles evaluated more favorably? Our central research question is: What are the (combined) effects of publicness and organizational structure on citizens' performance perceptions?

In order to guide academic scholarship, public administration research has conceptualized publicness through separate analytical dimensions, including ownership, funding and control (e.g. Perry \& Rainey, 1988; Boyne, 2002), and stresses that the public-private distinction should be seen as a continuum on which hybrid types exist (Bozeman, 1987). In the present study, we examine publicness not by means of these analytical dimensions, but rather regard publicness as a heuristic that guides citizens' information processing and performance evaluation (cf. Marvel, 2015; Hvidman \& Andersen, 2016; Hvidman 2019). In organizational theory, organizational structure refers to the way in which an organization separates the work into separate tasks and achieves coordination between these tasks. A bureaucratic structure is characterized by a high degree of standardization of organizational processes (cf. Mintzberg, 1979). Concerning performance, we distinguish between four dimensions of performance: effectiveness, efficiency, responsiveness, and equity. These dimensions correspond with multidimensional frameworks of public performance (e.g. Hood, 1991). Perceived effectiveness refers to the extent to which citizens perceive the organization to be successful in the attainment of the formal objectives of the organization. Perceived efficiency refers to the extent to which citizens perceive "an organization as being capable of containing its costs" (Hvidman \& Andersen, 2016, p. 114). Perceived responsiveness refers to the extent to which citizens perceive an organization to be open and reactive to feedback and criticism. Finally, perceived equity refers to the extent to which citizens perceive an organization to provide fair treatment to all citizens.

In order to assess the effects of publicness and bureaucratic structure on citizens' performance perceptions, we conduct a randomized survey-experiment among 422 Dutch Public Administration undergraduates. We use a 3 × 3 factorial design to isolate the direct and combined effects of both concepts on perceived organizational performance. The respondents are presented with descriptions of a fictitious organization that vary in terms of publicness (public/private/undisclosed) and organizational structure (bureaucratic/organic/undisclosed), and are asked to rate the performance of the organization.

\section{Organizational structure and publicness}

Mintzberg (1979) defines organizational structure as "the sum total of the ways in which it divides its labor into distinct tasks and then achieves coordination among them" (p. 2). According to Mintzberg (1979), a distinction can be made between bureaucratic structures at the one end and organic structures at the opposite end of the continuum. A bureaucratic organization is an organization in which the procedures are to a large extent standardized (Burns \& Stalker, 1961; Mintzberg, 1979). Bureaucratic organizations are characterized by "division of labour, specialization, formalization of behavior, hierarchy of authority, chain of command, regulated communication, and standardization of work processes and skills" (Mintzberg 1979, p. 85). Coordination of organizational behavior in a bureaucratic structure is achieved through standardization of processes, outputs and skills. The inverse of a bureaucratic structure is an organic structure where work processes are to a large extent unstandardized (e.g. Burns \& Stalker, 1966; Mintzberg, 1979). An organic structure is characterized by "loose, informal working relationships" and is "built on mutual adjustment" (Mintzberg 1979, p. 87). Coordination of organizational behavior is not achieved through standardization, but through direct supervision by the supervisor and informal, continuous communication between workers.

Given the nature of the tasks that public organizations perform and the particular values they are expected to satisfy, public organizations are - all else equal - characterized by highly bureaucratized organizational structures (Boyne, 2002). For instance, public organizations are expected to meet the demands of citizens and interest groups in a controllable and predictable manner (Gajduschek, 2003), to ensure that government processes are transparent and accountable, and to treat citizens in an unbiased and equal way (Kaufman, 1977). In addition, the work of many public organizations concerns routine tasks (Mintzberg, 1979), which implies that standardization is key to efficient operations. As a result, public organizations are (often) designed according to bureaucratic principles. Examples of such organizations are often large organizations that operate in relatively stable environments, such as the tax administration and the military. However, as a result of public management reforms and variation in the environment which public organizations operate, some public organizations are characterized by more organic forms of organizing such as decentralization, teamwork and deregulation 
(Groeneveld \& Van de Walle, 2011). Empirical examples of such trends can be witnessed in policy domains such as social welfare, health care and education. Depending on situational circumstances, private organizations can also differ considerably in their structural characteristics. For instance, a car manufacturer may exhibit many bureaucratic elements, as many aspects of its production process are highly standardized, whereas an architecture firm may be characterized by more organic, flexible structural arrangements.

According to Weber $(1947 ; 1978)$, a bureaucracy is the "ideal type" of structure for public organizations: hierarchy warrants accountability, formalization contributes to the equal treatment of citizens, and specialization protects employees and enables them to accomplish their jobs efficiently and effectively. Yet, Weber also acknowledges the downside of a bureaucratic structure: hierarchy, formalization, and specialization may also lead to the dehumanization of employees and through an excess of rules and regulations; what he called the iron cage of rationality. Other disadvantages of bureaucracy are the likelihood that rules and regulation become more important than organizational goals, a phenomenon Merton (1968) refers to as goal displacement, as well as trained incapacity (Velben, 1933), which refers to bureaucrats' inability to change and adapt stemming from prior training.

Because of these implications of a bureaucratic structure, "bureaucracy" has become a "dirty word" (Perrow, 1970, p. 50) which is often associated with rigid rules and regulations, impersonality, and resistance to change (Perrow, 1970), as well as inefficiency, ineffectiveness and irresponsiveness (Marvel, 2015). As a consequence, there is a public administration literature on the negative consequences of bureaucratic organizational forms, including research on red tape (Bozeman, 1993; Bozeman \& Feeney, 2011; Hattke et al., 2020) and administrative burden (Herd \& Moynihan, 2019; Christensen et al., 2020). According to Marvel (2015), citizens make automatic performance associations with the term bureaucracy, which color their assessments of public service delivery. Consequently, citizens evaluate the performance of public organizations more negatively than the performance private organizations. Some recent studies have indeed found a relationship between publicness and citizens' performance perceptions (Hvidman \& Andersen, 2016; Hvidman, 2019, study 2). Hvidman and Andersen (2016), for example, find that that Danish public hospitals are rated significantly lower on the performance dimensions efficiency and (low) red tape than private hospitals (yet, they find no such effects for the performance dimensions effectiveness and benevolence). Meier, Johnson, and An (2019), however, replicated the Danish study in the US and did not find any significant differences in the assessment of public and private hospitals. ${ }^{1}$ Comparably, Van den Bekerom, Van der Voet, and Christensen (2020) did also not find support for claims about a systematic, general effect of publicness on citizens' performance perceptions in the context of Dutch mass transit, maintaining public order and safety, and emergency ambulances. These inconsistent findings warrant further testing of the effect of publicness on citizens' performance perceptions (Meier et al., 2019), and in particular further insight into the extent that bureaucratic organizational structure functions as a mechanism that underlies the relationship.

\section{Hypothesis}

An important assumption of prior studies (e.g. Hvidman \& Andersen, 2016; Hvidman, 2019; Meier et al., 2019) is that citizens evaluate the performance of public organizations more negatively than the performance of private organizations because public organizations are associated with bureaucracy (and its negative connotation). Performance of public organizations, however, is a multidimensional concept that may comprise technical or productivity related aspects of performance, such as efficiency and effectiveness, but also normative or ethical aspects such as benevolence, equity and responsiveness. Hvidman and Andersen (2016) suggest that citizens' perceptions of these latter aspects of performance may not necessarily be negatively affected by publicness. As bureaucratic organizational structures make it easier to predict and check organizational processes and decisions (Gajduschek, 2003), it is possible that citizens associate bureaucratic public organizations with higher rather than lower levels of equity and responsiveness. For instance, bureaucratic rules and procedures may be perceived to guarantee adherence to laws and equal treatment, and to provide pathways for citizens to voice preferences or challenge decisions.

As the main argument in the literature on publicness and performance perceptions is that publicness reduces citizens' performance perceptions, this study tests the expectation that the effects of publicness are partly 
driven by citizens' perceptions that public organizations are bureaucratic. By operationally separating publicness and bureaucracy, we attempt to disentangle to what extent the bureaucratic nature of public organizations underlies the effect of publicness on performance perceptions. Given the negative connotations of the term "bureaucracy," as noted in the previous section, we expect that, relative to organizations with an organic structure, the negative effect of publicness on citizens' perceptions of the performance of public services is stronger for organizations with a bureaucratic structure. We formulate the following hypothesis:

Hypothesis: The (negative) effect of publicness on citizens'performance perceptions is strengthened by the presence of a bureaucratic organizational structure and weakened by the presence of an organic organizational structure.

\section{Methods}

\section{Survey-experiment}

In order to assess the moderating effect of organizational structure on the relationship between publicness and citizens' performance perceptions, we conducted a survey-experiment among 422 Dutch undergraduate students in public administration in the fall of 2016. Students were presented with a vignette about a fictitious organization. The vignettes varied in terms of publicness (public / private / undisclosed) and organizational structure (bureaucratic / organic / undisclosed). This $3 \times 3$ design resulted in nine experimental conditions (see Table 1). The experiment was conducted using a paper survey given to all students during first-, second- and third-year seminars. The students were randomly assigned to one of the nine experimental conditions. The vignette was followed by twelve questions about the performance of the organization, as well as two manipulations checks.

Table 1

Design of the survey-experiment

\begin{tabular}{lllll}
\hline \hline & & \multicolumn{3}{c}{ Organizational structure treatment } \\
& \multirow{2}{*}{ Public } & Bureaucratic & Organic & Undisclosed \\
\cline { 2 - 5 } & \multirow{2}{*}{ 1: Public \& } & 2: Public \& & 3: Public \& No \\
& Bureaucratic & Organic & structure \\
\cline { 2 - 5 } Sector treatment & 4: Private \& & 5: Private \& & 6: Private \& No \\
\cline { 2 - 5 } & \multirow{2}{*}{ Undisclosed } & Bureaucratic & Organic & structure \\
& Bureaucratic & 8: No sector \& & O: No sector \& \\
& & Organic & No structure \\
\hline
\end{tabular}

\section{Vignette}

The vignette used in the survey described a fictitious organization. Prior studies (e.g. Hvidman \& Andersen, 2016; Meier et al., 2019) rely on hospitals as the setting for a public-private comparison. For the purposes of this study, we believe the use of an explicit, familiar organization is unsuitable, because the use of an organizational type with which respondents are familiar might influence their perceptions of the organizational structure. For instance, hospitals are characterized by standardization of skills and standardization of processes, which precludes the extent to which perceptions of the organizational structures can be experimentally manipulated. We therefore choose to rely on a vignette of a fictitious organization that does not disclose any structural features: organization that facilitates citizens in their contact with government organizations, such as applying for subsidies, finding information, appealing against decisions, and complying with laws and regulations.

The vignette provided some basic information about the organization, including its tasks and goals. The vignette also included a report from an external consultancy firm that provided an overall assessment of the organization's performance. This information enabled respondents to form their judgement about the organization's performance (c.f., Hvidman \& Andersen, 2016). Table 2 shows the exact wording of the vignettes. Below, we discuss the experimental treatments. 


\section{Publicness}

Prior studies (e.g. Hvidman \& Andersen, 2016; Hvidman, 2018; Meier et al., 2019; Van den Bekerom et al., 2020) measured publicness using a public and a private sector cue, which allowed them to compare public versus private organizations. In the present study, we also test the separate effects of both cues by adding a control group. As the effect of publicness is expected to occur by means of an automatic and unconscious association (Marvel, 2015), the vignette relies on a relatively discrete manipulation. Experimental groups 1, 2, and 3 (see Table 1) were told that the fictitious organization is a "public organization." Groups 4, 5, and 6 were told that the organization is a "private organization." Groups 7, 8, and 9 (the control groups) did not receive the sector cue. Dummy variables were created for the three sector conditions.

\section{Organizational structure}

We operationalize organizational structure according to three of Mintzberg's (1979) structural parameters: the degree of specialization, the degree of standardization, and the degree of centralization. Groups 1, 4, and 7 received information about an organization with a bureaucratic structure and were told that "employees of the organization all perform a well-specified task. The work processes are fixed in written rules and procedures. The role of management consists of directing employees." Groups 2, 5, and 8 were given information about an organization with an organic structure and were told that "employees of the organization all perform a broad range of tasks. The work processes are coordinated among employees in mutual adjustment. The role of management consists of supporting employees." Groups 3, 6, and 9 received no information about the structure of the organization (the control groups). Dummy variables were created for the three structure conditions.

Table 2

\section{Vignette}

PJE is a/an [TREATMENT PUBLICNESS 0: no information given ; 1: public; 2: private] organization that facilitates citizens in their contact with government organizations. For example with applying for subsidies, finding information, appealing against decisions, and complying with laws and regulations.

The objective of PJE is to provide optimal services to citizens. The network of the organization consists of governments, knowledge institutions, business and several partner organizations.

[TREATMENT ORGANIZATIONAL STRUCTURE: 0: no information given] Employees of the organization all perform [1: a well-specified task; 2: a broad range of tasks]. The work processes are [1: fixed in written rules and procedures, 2: coordinated among employees in mutual adjustment]. The role of management consists of [1: directing / 2: supporting] employees.

The organization has recently hired a consultancy bureau to give an overall evaluation of the organization's performance. The consultants concluded that:

- "The organization uses modern technological means for communication and service delivery."

- "The buildings and facilities are in compliance with regulations about working conditions."

\section{Measures of performance perceptions}

Respondents were subsequently asked to rate the performance of the organization using 12 statements about the organization that measure four dimensions of performance: Efficiency, effectiveness, equity, and responsiveness (see Table 3 for the operationalization of these four dimensions). Respondents were asked to assess each statement on a five-point scale, ranging from 1 "completely disagree" to 5 "completely agree" (see Table 
A3 in the appendix for an overview of the means and standard deviations for all outcome variables across the 9 experimental groups). Although the experimental vignette contains relatively little performance information, prior research indicates that citizens are able to make meaningful performance evaluations in the absence of more extensive information or specific details (cf. Hvidman, 2019, p. 263).

To test the validity of these four dimensions, we conducted a confirmatory factor analysis (for the results of the confirmatory factor analysis see Figure A1 in the Appendix), which confirms that the 12 items load on the four performance dimensions. The goodness of fit statistics indicated an overall good fit: CFI $=0.932$, TLI $=0.907$, RMSEA $=0.066, \mathrm{SRMR}=0.053$.

In addition, we compared the fit of the model to two alternative models: a one-factor model and a twofactor model (factor 1 = effectiveness and efficiency, factor 2 = equity and responsiveness). The fit statistics for these measurement models are presented in Table 4. As the results show, the one-factor and two-factor models do not improve the goodness of fit statistics of the original four-factor model, which demonstrates construct validity of the four performance perception measures. We use the factor scores to measures the four performance dimensions. We note that the composite reliability for efficiency and responsiveness is below commonly accepted thresholds, which indicates that responses to the three items used in these measures are not highly internally consistent (cf. Meier et al., 2019).

Table 3

\section{Operationalization of perceived performance}

- “The organization provides value for money" (Andrews \& Van de Walle, 2013)

Efficiency - "This organization is effective in lowering costs" (Hvidman \& Andersen, 2016)

- “This organization prioritizes a healthy budget” (Hvidman \& Andersen, 2016)

- This organization is effective in accomplishing its goals

- "This organization is effective in accomplishing its core mission" (Hvidman \&

Effectiveness Andersen, 2016)

- "This organization is effective in delivering a very good service" (Hvidman \& Andersen, 2016)

\begin{tabular}{|c|c|}
\hline Equity & $\begin{array}{l}\text { - "[the organization] treat[s] all types of people fairly" (Andrews \& Van de Walle, } \\
\text { 2013) } \\
\text { - This organization treats all types of people equally } \\
\text { - This organization treats all types of people justly }\end{array}$ \\
\hline $\begin{array}{l}\text { Responsive- } \\
\text { ness }\end{array}$ & $\begin{array}{l}\text { - "[clients are] treated with respect and consideration" (Andrews \& Van de Walle, } \\
\text { - } 2013 \text { ) } \\
\text {-This organization responds to requests quickly and adequate" (Vigoda, 2000) } \\
\text { - "This organization seriously responds to criticism and suggestions for improve- } \\
\text { ment" (Vigoda, 2000) }\end{array}$ \\
\hline
\end{tabular}

Categories: 1 = Completely disagree, $2=$ Disagree, $3=$ Neither agree nor disagree, $4=$ Agree, $5=$ Completely agree; $\mathrm{CR}=$ Composite Reliability 
Table 4

Model fit statistics (alternative) measurement models

\begin{tabular}{lllll}
\hline \hline & RMSEA & CFI & TLI & SRMR \\
4-factor model & .066 & .932 & .907 & .053 \\
2-factor model & .098 & .832 & .791 & .085 \\
1-factor model & .117 & .758 & .704 & .081 \\
\hline
\end{tabular}

\section{Randomization, balance, manipulation checks, and statistical power}

In order to check for successful randomization, the survey also included questions about the respondents' background characteristics: students' gender; age; their future job sector preference; whether they were firstyear, second-year, or third-year undergraduates; public service motivation; bureaucratic tolerance; and political ideology (the operationalization of these background variables can be found in Table A2 in the Appendix). Table 5 provides the summaries of the descriptive statistics of these background variables, as well as the results of an F-test comparing the means of the background variables in order to check whether the experimental groups were balanced. As Table 5 shows, we do not find and systematic differences in the distribution of the background variables, which indicates that the randomization of the nine experimental groups was successful.

We also included two manipulation checks. The first manipulation check measured whether respondents perceived the sector of the organization correctly. We asked respondents whether the organization described in the vignette was "public," "private," or "don't know." Out of the 281 respondents who were assigned to either the bureaucratic structure or organic structure condition and answered the manipulation check, 24 (8,5 percent) misidentified the status of the organization, 36 (12.8 percent) respondents stated that they did not know the status of the organization, and 221 (78.6 percent) correctly identified sector of the organization. These results are comparable with the manipulation check reported by Hvidman and Andersen (2016).

To assess whether respondents perceived the organizational structure manipulation as intended, we asked the respondents whether the organization in the vignette was bureaucratic $(1=$ Strongly disagree; 2 = Disagree; $3=$ Neither agree nor disagree; $4=$ Agree; $5=$ Strongly agree). To test whether the three treatment groups differ from one another in terms of this second manipulation check, we carried out a t-test comparing the bureaucratic group to both the organic and the control group. The results show that the believe that the organization is bureaucratic is stronger for respondents in the bureaucratic group $(\mathrm{M}=3.53, \mathrm{SD}=0.86)$ compared to both the organic group $(\mathrm{M}=3.00, \mathrm{SD}=0.80), \mathrm{t}(271)=5.23, \mathrm{p}=0.000$, and the control group $(\mathrm{M}=3.21$, $\mathrm{SD}=0.75), \mathrm{t}(276)=3.39, \mathrm{p}=0.000$.

Because the 422 students were randomly assigned to one of the nine experimental conditions, the average group size is 47 . To find out whether our design had enough power to detect a statistically significant effect of the interaction between publicness and organizational structure, we conducted a post hoc power analysis with the program $G^{*}$ Power (Erdfelder, Faul, \& Buchner, 1996) with effect size (d) set at 0.30 and group size set at 47. The analysis indicated that there is only a 30 percent chance of detecting a 0.30 effect size for the interactions between publicness and organizational structure at the 5\% level (two-tailed). This means that possible nullfindings can be attributed to a limited sample size. Hence, a careful and cautious interpretation of results is warranted. 


\section{Table 5}

Descriptive statistics and balance check

\begin{tabular}{|c|c|c|c|c|c|c|c|c|c|c|c|c|c|c|}
\hline & \multicolumn{4}{|c|}{ Descriptives } & \multicolumn{10}{|c|}{ Balance check } \\
\hline & \multirow[b]{2}{*}{ Mean } & \multirow[b]{2}{*}{ Std. Dev. } & \multirow[b]{2}{*}{ Min } & \multirow[b]{2}{*}{ Max } & \multicolumn{3}{|c|}{ No sector } & \multicolumn{2}{|c|}{ Public sector } & \multicolumn{5}{|c|}{ Private sector } \\
\hline & & & & & No structure & Bureaucratic & Organic & No structure & Bureaucratic & Organic & No structure & Bureaucratic & Organic & $F$ \\
\hline Gender $=$ female & .44 & .50 & 0 & 1 & .49 & .45 & .51 & .54 & .36 & .42 & .35 & .51 & .28 & 1.66 \\
\hline Age & 20.46 & 2.37 & 17 & 36 & 20.30 & 20.74 & 19.87 & 20.29 & 20.06 & 20.93 & 20.52 & 20.67 & 20.84 & 1.05 \\
\hline Sector preference $=$ public & .24 & .43 & 0 & 1 & .35 & .36 & .21 & .19 & .23 & .24 & .19 & .23 & .19 & 1.05 \\
\hline Sector preference $=$ private & .27 & .45 & 0 & 1 & .26 & .23 & .43 & .25 & .26 & .18 & .29 & .33 & .23 & .96 \\
\hline Sector preference $=$ none & .48 & .50 & 0 & 1 & .40 & .40 & .36 & .56 & .51 & .58 & .52 & .44 & .58 & 1.07 \\
\hline Year 1 & .46 & .50 & 0 & 1 & .42 & .47 & .47 & .48 & .49 & .44 & .44 & .44 & .51 & .10 \\
\hline Year 2 & .35 & .48 & 0 & 1 & .37 & .38 & .34 & .33 & .34 & .36 & .40 & .35 & .30 & .09 \\
\hline Year 3 & .18 & .39 & 0 & 1 & .21 & .15 & .19 & .19 & .17 & .20 & .17 & .21 & .19 & .10 \\
\hline Public service motivation & 3.90 & .71 & 1 & 5 & 3.77 & 4.07 & 3.74 & 4.03 & 3.90 & 3.93 & 3.82 & 3.97 & 3.85 & 1.14 \\
\hline Bureaucratic tolerance & 2.74 & .53 & 1 & 4.5 & 2.76 & 2.65 & 2.83 & 2.83 & 2.78 & 2.64 & 2.70 & 2.63 & 2.88 & 1.61 \\
\hline Ideology & 5.84 & 1.74 & 1 & 10 & 5.53 & 5.43 & 6.15 & 5.75 & 6.13 & 5.73 & 6.21 & 5.74 & 5.88 & 1.48 \\
\hline $\mathrm{N}$ & & & & & 44 & 47 & 48 & 49 & 50 & 46 & 49 & 44 & 45 & 422 \\
\hline
\end{tabular}




\section{Results}

Table 6 presents the results of the ordinary least squares (OLS) regression analysis. Our central hypothesis predicts that the (negative) effect of publicness on citizens' performance perceptions is strengthened by the presence of a bureaucratic organizational structure and weakened by the presence of an organic organizational structure.

Model 1 tests the direct effect of publicness on efficiency, effectiveness, equity, and responsiveness (with private sector as the reference category). We find that all coefficients are positive but lack statistical significance. Hence, our results suggest that citizens' perceptions about the performance of public organizations is not worse than their perceptions about the performance of private organizations. We do find that respondents in the control group are significantly less positive about how efficient the organization is than respondents in the private sector groups.

Model 2 tests the direct effect of organizational structure (with organic structure as the reference group). The coefficients of the bureaucratic structure dummy variable are predominantly negative (except for equity), but again, lack statistical significance. This suggests that citizens' perceptions about the performance of an organization with a bureaucratic structure is not worse than people's perceptions about the performance of an organization with an organic structure.

Model 3 adds the interactions between sector and organizational structure. The results show that the coefficients for the interaction between public sector and bureaucratic structure are positive, but only the coefficient of the effect on responsiveness is statistically significant. To simplify the interpretation of these interactions, we visualized the marginal effects of publicness in Figure 1 (both control groups were excluded from the figure). We find that for both efficiency and effectiveness, the presence of a bureaucratic structure does not significantly influence citizens' performance perceptions about the public organization. For equity and responsiveness, however, we find evidence of an interaction effect between publicness and the presence of a bureaucratic structure. As is visualized in Figure 1, the effect of publicness is positive and statistically significant when the organization has a bureaucratic organizational structure. For both dimensions of performance, the public organization is evaluated more positively when it is characterized by a bureaucratic structure. ${ }^{2}$ We thus find support - though in the reverse direction-for our expectation that the effect of publicness in combination with a bureaucratic structure is different from the effect of publicness in combination with an organic structure: compared to public organizations with an organic structure, respondents are more positive about the performance of public organizations with a bureaucratic structure in terms of equity and responsiveness. 
Table 6

OLS regression analysis (unstandardized coefficients; standard error between parentheses; $n=422$ )

\begin{tabular}{|c|c|c|c|c|c|c|c|c|c|c|c|c|}
\hline & \multicolumn{3}{|c|}{ Efficiency } & \multicolumn{3}{|c|}{ Effectiveness } & \multicolumn{3}{|c|}{ Equity } & \multicolumn{3}{|c|}{ "Responsiveness } \\
\hline & M1 & M2 & M3 & M1 & M2 & M3 & M1 & M2 & M3 & M1 & M2 & M3 \\
\hline Public sector $^{\mathrm{a}}$ & $\begin{array}{c}.001 \\
(.032)\end{array}$ & & $\begin{array}{l}-.060 \\
(.056)\end{array}$ & $\begin{array}{c}.033 \\
(.045)\end{array}$ & & $\begin{array}{l}.086 \\
(.080)\end{array}$ & $\begin{array}{c}.075 \\
(.058)\end{array}$ & & $\begin{array}{l}-.057 \\
(.103)\end{array}$ & $\begin{array}{c}.035 \\
(.037)\end{array}$ & & $\begin{array}{l}-.071 \\
(.065)\end{array}$ \\
\hline No sector $^{\mathrm{a}}$ & $\begin{array}{c}-.057^{*} \\
(.032)\end{array}$ & & $\begin{array}{c}-.094 * \\
(.055)\end{array}$ & $\begin{array}{l}-.032 \\
(.046)\end{array}$ & & $\begin{array}{l}-.101 \\
(.079)\end{array}$ & $\begin{array}{c}.038 \\
(.059)\end{array}$ & & $\begin{array}{l}-.031 \\
(.101)\end{array}$ & $\begin{array}{l}-.016 \\
(.038)\end{array}$ & & $\begin{array}{l}-.074 \\
(.065)\end{array}$ \\
\hline Bureaucratic structure ${ }^{b}$ & & $\begin{array}{l}-.019 \\
(.032)\end{array}$ & $\begin{array}{l}-.052 \\
(.057)\end{array}$ & & $\begin{array}{l}-.016 \\
(.046)\end{array}$ & $\begin{array}{l}-.081 \\
(.081)\end{array}$ & & $\begin{array}{c}.020 \\
(.059)\end{array}$ & $\begin{array}{l}-.068 \\
(.104)\end{array}$ & & $\begin{array}{l}-.009 \\
(.037)\end{array}$ & $\begin{array}{l}-.069 \\
(.066)\end{array}$ \\
\hline No structure ${ }^{b}$ & & $\begin{array}{l}-.008 \\
(.032)\end{array}$ & $\begin{array}{l}-.073 \\
(.055)\end{array}$ & & $\begin{array}{l}-.024 \\
(.046)\end{array}$ & $\begin{array}{c}-.145^{*} \\
(.079)\end{array}$ & & $\begin{array}{c}.019 \\
(.058)\end{array}$ & $\begin{array}{l}-.093 \\
(.101)\end{array}$ & & $\begin{array}{l}-.014 \\
(.037)\end{array}$ & $\begin{array}{c}-.116^{*} \\
(.064)\end{array}$ \\
\hline Public $*$ Bureaucratic & & & $\begin{array}{c}.074 \\
(.079)\end{array}$ & & & $\begin{array}{c}.173 \\
(.112)\end{array}$ & & & $\begin{array}{c}.226 \\
(.144)\end{array}$ & & & $\begin{array}{l}.159 * \\
(.092)\end{array}$ \\
\hline Public $*$ No structure & & & $\begin{array}{c}.104 \\
(.078)\end{array}$ & & & $\begin{array}{c}.174 \\
(.111)\end{array}$ & & & $\begin{array}{c}.160 \\
(.142)\end{array}$ & & & $\begin{array}{l}.150^{*} \\
(.091)\end{array}$ \\
\hline No sector $*$ Bureaucratic & & & $\begin{array}{c}.024 \\
(.079)\end{array}$ & & & $\begin{array}{c}.014 \\
(.113)\end{array}$ & & & $\begin{array}{c}.027 \\
(.144)\end{array}$ & & & $\begin{array}{c}.014 \\
(.092)\end{array}$ \\
\hline No sector $*$ No structure & & & $\begin{array}{c}.087 \\
(.078)\end{array}$ & & & $\begin{array}{l}.189 * \\
(.112)\end{array}$ & & & $\begin{array}{c}.181 \\
(.144)\end{array}$ & & & $\begin{array}{l}.157^{*} \\
(.091)\end{array}$ \\
\hline Constant & $\begin{array}{c}.020 \\
(.023)\end{array}$ & $\begin{array}{c}.010 \\
(.023)\end{array}$ & $\begin{array}{c}.063 \\
(.040)\end{array}$ & $\begin{array}{c}.004 \\
(.033)\end{array}$ & $\begin{array}{c}.018 \\
(.032)\end{array}$ & $\begin{array}{c}.081 \\
(.057)\end{array}$ & $\begin{array}{l}-.032 \\
(.042)\end{array}$ & $\begin{array}{l}-.006 \\
(.042)\end{array}$ & $\begin{array}{c}.023 \\
(.073) \\
\end{array}$ & $\begin{array}{l}-.003 \\
(.027)\end{array}$ & $\begin{array}{c}.012 \\
(.027)\end{array}$ & $\begin{array}{c}.060 \\
(.046)\end{array}$ \\
\hline $\mathrm{R}^{2}$ & .010 & .001 & .017 & .005 & .001 & .021 & .004 & .000 & .016 & .005 & .000 & .023 \\
\hline
\end{tabular}

Notes: ${ }^{*} \mathrm{p}<.10,{ }^{* *} \mathrm{p}<.05,{ }^{* * *} \mathrm{p}<.01$, using a two-tailed t-test; a) reference category is private organization; b) reference category is organic structure. 
Figure 1

Marginal effects of publicness on performance evaluation conditional on organizational structure, with $90 \%$ confidence intervals
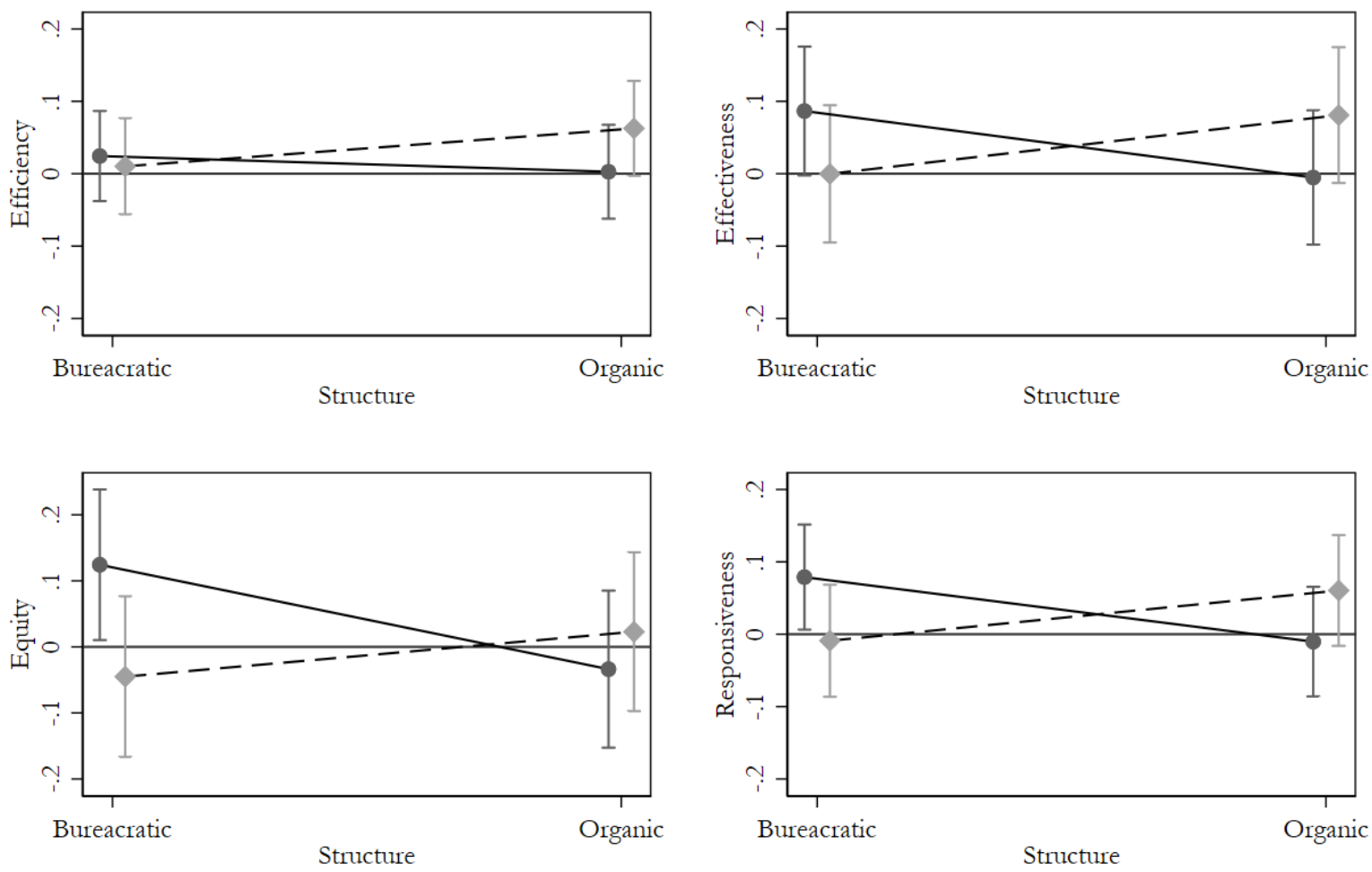

$\longrightarrow$ Public organization $\quad-\bullet--$ Private organization

\section{Conclusion and Discussion}

The aim of this article was to examine to what extent the proclaimed negative effect of publicness on citizens' performance perceptions is dependent on citizens' perceptions regarding the bureaucratic nature of public organizations. By means of a survey-experiment in which we disentangle these two variables, our study contributes to debates about the effect of publicness on citizens' performance perceptions in several ways.

A first contribution is that we do not find evidence that citizens rate the performance of public organizations more negatively. Recent evidence from the American context (Meier et al., 2019) did not corroborate initial findings obtained among Danish citizens (Hvidman \& Andersen, 2016; Hvidman, 2019). This study suggests that publicness effects may indeed not be universal among citizens, even among citizens such as Public Administration undergraduates that can be expected to be likely to detect such public-private differences as a result of their education and interests.

The second contribution concerns the main aim of this article, which was to examine the interaction between publicness and structural characteristics of the organization. Congruent with our general theoretical assumption that the structural features of a public organization are relevant for citizens' performance perceptions, but in contrast with our theoretical expectation that bureaucratic structural characteristics worsen the performance perceptions that citizens hold of public organization, our study suggests that bureaucratic structures positively affect the degree in which citizens perceive public organizations to be equitable and responsive. The results indicate that public organizations with a bureaucratic structure are perceived to be more equitable 
and responsive than private organizations with a bureaucratic structure, as well as public organizations with an organic structure. These findings suggest that the relationship between organizational structure and perceived performance of public organizations is situational. For some dimensions of public performance (Hood's (1991) Theta and Lambda values), bureaucratic structures may offer inherent benefits, while not for values related to effectiveness and efficiency (Hood's Sigma values). As discussed in the theory section, these divergent results may potentially arise because different mechanisms underlie the relationships between publicness and dimensions of performance. For public organizations, the presence of formal rules and procedures may signal predictability and controllability of organizational processes and decisions (cf. Gajduschek, 2003), thereby strengthening rather than impeding perceived equity and responsiveness.

The present study also has a number of limitations. Most importantly, our findings must be tempered by an awareness of the limited statistical power. The modest sample size in the present study and the subsequent low statistical power may have played a role in limiting the significance of the group comparisons conducted. Consequently, the present study should be viewed as an exploratory study on the interaction between publicness and structural characteristics that future studies can build upon. Furthermore, the specific national context of this study limits the extent to which our results travel to other national contexts. The fact that, by international standards, The Netherlands is characterized by well-functioning public services and relatively high trust in government and the public sector, may also explain why we find a positive effect of a bureaucratic organizational structure on the degree in which citizens perceive public organizations to be equitable and responsive. Negative effects of publicness on citizens' performance perceptions are likely to be strengthened by bureaucratic organizational structures in other countries with greater antigovernment rhetoric.

We conclude that future Behavioral Public Administration research may generate greater insight into the relationship between publicness and citizens' performance perceptions by paying more attention to the contingencies that underlie this relationship. Our study mirrors the results by Hvidman (2019) and Hvidman and Andersen (2016) in the sense that publicness may have divergent effects on the range of values that underlie public performance. Prior studies have also indicated that publicness effects are not universal, but highly driven by processes of motivated reasoning: the prior political preferences and attitudes of citizens determine if and to what extent they negatively perceive the performance of public vis-à-vis private organizations (e.g., Van den Bekerom et al., 2020). Our study signals that the characteristics of organizations also explain variation between citizens' performance perceptions about public and private organizations. Given that the classic public administration literature on publicness (e.g. Bozeman, 1987; Boyne, 2002) indicates that the public-private distinction should be understood as a continuum rather than a dichotomy, future Behavioral Public Administration research may fruitfully examine citizens' performance perceptions regarding more hybrid governance arrangements such as state-owned enterprises, cross-sector governance networks and public-private partnerships.

\section{Notes}

1. More recently, Meier and An (2020) also published the results of an extension of the Hvidman and Andersen (2016) study that was included in the Meier et al. (2019) study. Next to a public and private sector cue, they added a nonprofit organization cue, and again found no sectoral differences in performance perceptions.

2. To test the robustness of our results, we repeated the analyses using a sample without participants who failed the manipulation check. The analysis shows that our results are highly robust (results are available upon request). 


\section{References}

Andrews, R., \& Van de Walle, S. (2013). New public management and citizens' perceptions of local service efficiency, responsiveness, equity and effectiveness. Public Management Review, 15(5), 762-783.

Baker, S. H., Etzioni, A., Hansen, R. A., \& Sontag, M. (1973). Tolerance for bureaucratic structure: Theory and measurement. Human Relations, 26(6), 775-786.

Bekerom, P.E.A. van den, Van der Voet, J. \& Christensen, J. (2020). Are citizens more negative about failing service delivery by public organizations than by private organizations? Evidence from a large-scale survey experiment. Journal of Public Administration Research and Theory. Online advance access. https://doi.org/10.1093/jopart/muaa027

Boyne, G. A. (2002). Public and private management: what's the difference? Journal of management studies, 39(1), 97-122.

Bozeman, B. (1987). All organizations are public: Bridging public and private organizational theories. Jossey-Bass Inc Pub.

Bozeman, B. (1993). A theory of government "red tape". Journal of public administration research and theory, 3(3), 273-304.

Burns, T. E., \& Stalker, G. M. (1961). The Management of Innovation (SSRN Scholarly Paper No. ID 1496187). Rochester, NY: Social Science Research Network.

Christensen, J., Aarøe, L., Baekgaard, M., Herd, P., \& Moynihan, D. P. (2020). Human Capital and Administrative Burden: The Role of Cognitive Resources in Citizen-State Interactions. Public Administration Review, 80(1), 127-136.

Erdfelder, E., Faul, F., \& Buchner, A. (1996). GPOWER: A general power analysis program. Behavior research methods, instruments, \& computers, 28(1), 1-11.

Gajduschek, G. (2003). Bureaucracy: Is it efficient? Is it not? Is that the question? Uncertainty reduction: An ignored element of bureaucratic rationality. Administration \& Society, 34(6), 700-723.

Groeneveld, S., \& Van de Walle, S. (2011). New steering concepts in public management, Research in Public Policy Analysis and Management.

Hattke, F., Hensel, D., \& Kalucza, J. (2020). Emotional responses to bureaucratic red tape. Public Administration Review, 80(1), 53-63.

Herd, P., \& Moynihan, D. P. (2019). Administrative burden: Policymaking by other means. Russell Sage Foundation.

Hood, C. (1991). A public management for all seasons?. Public administration, 69(1), 3-19.
Hvidman, U. (2019). Citizens' Evaluations of the Public Sector: Evidence From Two Large-Scale Experiments. Journal of Public Administration Research and Theory, 29(2), 255-267.

Hvidman, U., \& Andersen, S. C. (2016). Perceptions of Public and Private Performance: Evidence from a Survey Experiment. Public Administration Review, 76(1), 111-120.

Kaufman, H. (1977). Red tape: Its origins, uses, and abuses. Washington, DC: The Brookings Institution.

Marvel, J. D. 2015. Unconscious bias in citizens' evaluations of public sector performance. Journal of Public Administration Research and Theory 26 (1): 143-158.

Meier, K. J., \& An, S. H. (2020). Sector bias in public programs: US nonprofit hospitals. Journal of Behavioral Public Administration, 3(1).

Meier, K. J., Johnson, A. P., \& An, S. H. (2019). Perceptual Bias and Public Programs: The Case of the United States and Hospital Care. Public Administration Review, 79(6), 820-828.

Merton, R. K., \& Merton, R. C. (1968). Social theory and social structure. Simon and Schuster.

Mintzberg, H. (1979). The structuring of organization. A Synthesis of the Research. Englewood Cliffs, NJ.

Perrow, C. B. (1970). Organizational analysis: A sociological view. Brooks/Cole.

Perry, J. L., \& Rainey, H.G. (1988). The Public-Private Distinction in Organization Theory: A Critique and Research Strategy. Academy of Management Review, 13(2), 182-201.

Veblen, T. (1933). The Engineers and the Price System. New York: Viking.

Vigoda, E. (2000). Are you being served? The responsiveness of public administration to citizens' demands: An empirical examination in Israel. Public Administration, 78(1), 165-191.

Weber, M. (1947). The theory of social and economic organization, ed. T. Parsons. New York: Oxford University Press.

Weber, M. (1978). From Max Weber: Essays in sociology, ed. H. H. Gerth and C. Wright Mills. New York: Galaxy Books. 


\section{Appendix}

Figure A1

Results of the confirmatory factor analysis

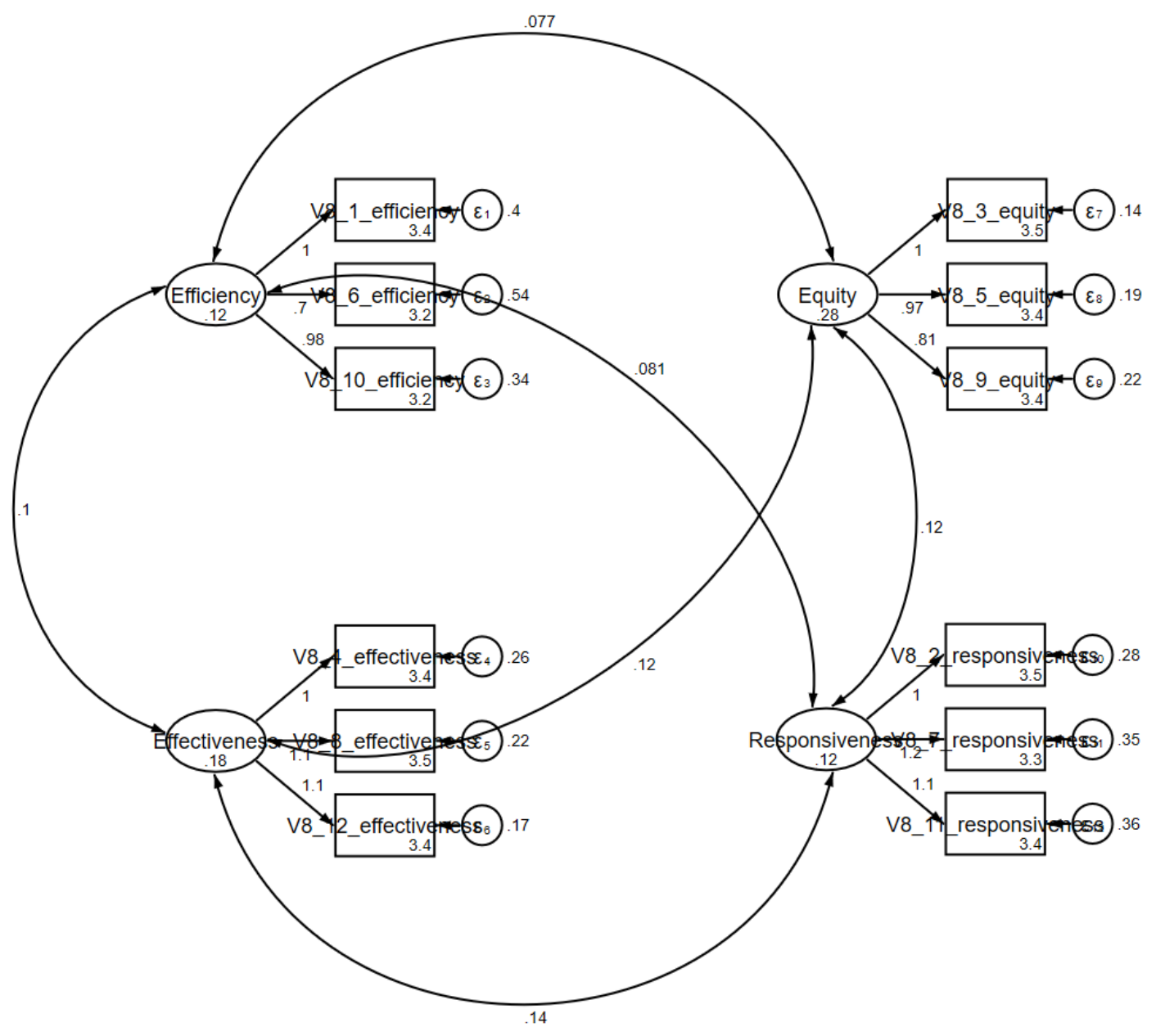


Table A2

Operationalization of background characteristics

Ideology

Sector preference

Public Service Motivation

Bureaucratic tolerance
- On a scale from 0 to 10 , where ' 0 ' stands for 'extreme left' and ' 10 ' stands for 'extreme right', where do you place yourself concerning your political preference for economic policy? Extreme left means that you want the government to have a very large role, with relatively high taxes and much regulation. Extreme right means that you want the government to have a very small role, with relatively low taxes and little regulation.

- In which sector would you like to work after finishing your studies?

Categories: $1=$ public, $2=$ private, $3=$ no preference

- It is important to me that my future job contributes to the life of others (Hvidman \& Andersen, 2015)

- It is important to me that my future job is useful for society (Hvidman \& Andersen, 2015)

Categories: 1 = Strongly disagree, $2=$ Disagree, $3=$ Neither agree nor disagree, $4=$ Agree, $5=$ Strongly agree

- Even if I dislike a rule, I usually obey it. (Baker et al., 1973)

- Often, the only thing wrong with breaking rules is getting caught. (Baker et al., 1973)

Categories: $1=$ Strongly disagree, $2=$ Disagree, $3=$ Neither agree nor disagree, $4=$ Agree, $5=$ Strongly agree 


\section{Table A3}

Means and standard deviations for all outcome variables across the 9 experimental groups

\begin{tabular}{|c|c|c|c|c|c|c|c|c|c|c|c|c|c|c|c|c|c|c|}
\hline & \multicolumn{6}{|c|}{ No sector } & \multicolumn{6}{|c|}{ Public sector } & \multicolumn{6}{|c|}{ Private sector } \\
\hline & \multicolumn{2}{|c|}{ No structure } & \multicolumn{2}{|c|}{ Bureaucratic } & \multicolumn{2}{|c|}{ Organic } & \multicolumn{2}{|c|}{ No structure } & \multicolumn{2}{|c|}{ Bureaucratic } & \multicolumn{2}{|c|}{ Organic } & \multicolumn{2}{|c|}{ No structure } & \multicolumn{2}{|c|}{ Bureaucratic } & \multicolumn{2}{|c|}{ Organic } \\
\hline & Mean & Std. Dev. & Mean & Std. Dev. & Mean & Std. Dev. & Mean & Std. Dev. & Mean & Std. Dev. & Mean & Std. Dev. & Mean & Std. Dev. & Mean & Std. Dev. & Mean & Std. Dev. \\
\hline Efficiency & 3.11 & .44 & 3.18 & .56 & 3.18 & .47 & 3.32 & .59 & 3.21 & .51 & 3.26 & .41 & 3.28 & .51 & 3.29 & .46 & 3.32 & .44 \\
\hline Effectiveness & 3.46 & .54 & 3.35 & .53 & 3.40 & .57 & 3.39 & .56 & 3.53 & .56 & 3.43 & .47 & 3.35 & .52 & 3.48 & .54 & 3.52 & .42 \\
\hline Equity & 3.54 & .46 & 3.38 & .66 & 3.40 & .52 & 3.47 & .67 & 3.57 & .56 & 3.41 & .51 & 3.35 & .58 & 3.37 & .54 & 3.39 & .44 \\
\hline Responsiveness & 3.40 & .40 & 3.25 & .53 & 3.42 & .52 & 3.51 & .54 & 3.53 & .49 & 3.34 & .38 & 3.33 & .60 & 3.32 & .53 & 3.50 & .45 \\
\hline
\end{tabular}

